\title{
The effect of postoperative complications on health-related quality of life and survival 12 years after coronary artery bypass grafting - a prospective cohort study
}

Matti Hokkanen ${ }^{1,2^{*}}$ (D) Heini Huhtala ${ }^{3}$, Jari Laurikka ${ }^{1,2}$ and Otso Järvinen ${ }^{1}$

\begin{abstract}
Background: Despite the steady improvements in survival and operative safety, postoperative complications still remain a significant cause of morbidity and mortality after coronary artery bypass grafting (CABG). However, less is known on the impact of postoperative complications on health-related quality of life (QoL). The main objective of our study was to investigate the impact of postoperative complications on long-term QoL and survival after CABG surgery.
\end{abstract}

Methods: Data of 508 patients, who underwent isolated CABG was prospectively collected. The RAND-36 Health Survey (RAND-36) was used to evaluate patients' QoL status preoperatively, 1 year and 12 years after the surgery. Predefined postoperative complications were reported during primary and secondary hospital stay. QoL and survival analysis were performed primarily on three patient groups: patients with and without complications and patients with major adverse cardiac and cerebrovascular events (MACCE).

Results: In total 205(40\%) of 508 patients had at least one postoperative complication and 73 (14\%) experienced MACCE. Patients' thirty-day, 1-year and 10-year survival rates were, 99, 98, 84\% without complications, 97, 95, 72\% with complications, and 90, 89, 64\% with MACCE, respectively (log-rank $p<0.001$ ). Patients without complications showed significant $(p<0.05)$ improvements in seven and patients with complications in five out of eight RAND-36 QoL dimensions. All patient groups showed significant improvements in RAND-36 summary scores compared with preoperative values. Patients with complications and especially with MACCE had more profound decline in their RAND-36 summary scores while patients without complications maintained their health status best.

Conclusions: Despite the constant deterioration, both patients with and without complications showed improvements even 12 years after CABG compared with preoperative state. Postoperative complications and especially MACCE were associated with impaired long-term QoL.

Keywords: Coronary artery bypass, Quality of life, Outcomes, Survival, Postoperative complication

\footnotetext{
* Correspondence: matti.hokkanen@fimnet.fi

'Department of Cardio-Thoracic Surgery, Tays Heart Hospital, Tampere University Hospital, Tampere, Finland

${ }^{2}$ Faculty of medicine and health technology, Tampere University, Tampere, Finland

Full list of author information is available at the end of the article
}

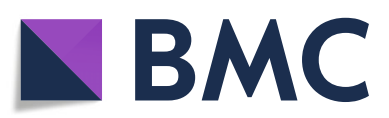

(- The Author(s). 2021 Open Access This article is licensed under a Creative Commons Attribution 4.0 International License, which permits use, sharing, adaptation, distribution and reproduction in any medium or format, as long as you give appropriate credit to the original author(s) and the source, provide a link to the Creative Commons licence, and indicate if changes were made. The images or other third party material in this article are included in the article's Creative Commons licence, unless indicated otherwise in a credit line to the material. If material is not included in the article's Creative Commons licence and your intended use is not permitted by statutory regulation or exceeds the permitted use, you will need to obtain permission directly from the copyright holder. To view a copy of this licence, visit http://creativecommons.org/licenses/by/4.0/ The Creative Commons Public Domain Dedication waiver (http://creativecommons.org/publicdomain/zero/1.0/) applies to the data made available in this article, unless otherwise stated in a credit line to the data. 


\section{Background}

Coronary artery bypass grafting (CABG) has remained the most commonly performed cardiac surgery procedure over the past decades [1]. The main goal of the surgery is to improve survival and health related quality of life (QoL) [2]. Despite the fact that the profile of patients undergoing isolated CABG surgery has changed towards higher age with increased frequency of preoperative comorbidities [3, 4] mortality and severe morbidity after CABG have even decreased over past decades $[1,5]$. However, the life-expectancy of older and more moribund patients may be limited due to natural causes which emphasizes the importance of QoL as indication for surgery.

Whilst CABG surgery's safety and efficacy in treating patients with coronary artery disease (CAD) is wellestablished, the complications of the surgery still remain a burden causing mortality, morbidity and decrease in QoL [5]. The outcomes of CABG surgery are mainly studied in terms of survival benefit and relief from cardiac related symptoms. Yet, there is a lack of long-term data on the effects of postoperative complications on QoL. In this prospective cohort study we evaluated the impact of postoperative complications on long term health related QoL and survival 12 years after CABG procedure. Special interest was focused on the impact of major adverse cardiac and cerebrovascular events (MACCE) on postoperative quality of life.

\section{Methods}

The original data on operations were obtained from Tampere University Hospital between May 1999 and November 2000. The study was approved by the institutional review board of Tampere university and all participating patients gave informed consent. The study cohort included 508 patients who had CABG surgery electively or urgently. Extensive medical data was prospectively collected pre-, per- and postoperatively during primary hospital stay. Majority of patients were discharged to 18 local district hospitals and data from these hospitals were collected by referring physicians and send to authors for further analysis. All predefined complications and outcome events were recorded for joint analysis with the primary hospital data. Statistical Finland provided survival data and dates of death after discharge and also survival data for age-, sex- and hospitalcatchment-area-matched controls (1:3).

Total number of patients operated in Tampere University Hospital during study period was 1128 . Patients who were emergently operated or unable to complete the survey were excluded. In comparison to 508 included patients, the excluded ones were less often male (402 (65\%) vs. $420(83 \%)$ patients $p<0.001$ ), were older (mean age 67 vs 62 years $p<0.001$ ), were operated more urgently (293 (47\%) vs $109(22 \%)$ patients $p<0.001)$, had more often ejection fraction under 50\% (166 patients $(28 \%)$ vs $92(18 \%)$ patients $p<0.001)$, had more often history of stroke $(43(6.9 \%)$ vs $20(3.9 \%)$ patients, $p=$ $0.036)$ or diabetes $(119(19 \%)$ vs $74(15 \%)$ patients $p=$ 0.47). Preoperative characteristics of the patient groups are shown in Table 1.

First, a baseline QoL questionnaire was given to patients 1 day before surgery. Follow-up questionnaires were mailed to patients 1 year and 12 years after surgery. During the first postoperative year 17 patients (3\%) died and 465 (95\%) of 491 surviving patients returned the one-year follow-up questionnaire, mean follow-up time being 12.6 months (SD 1.2). Those 26 patients who did not complete the one-year follow-up survey, were younger (median age 54 vs. 63 years $p=0.006$ ) in comparison to 465 patients who completed it. Otherwise the groups were closely similar in terms of sex, Euroscore 1 risk sum, priority of operation or NYHA glass. Next, the same follow-up questionnaire was mailed to patients 12 years after the surgery median follow-up time being 11.8 years (SD 0.48). Two hundred and 96 patients had died during this second follow-up period and 296 (84\%) of the 354 surviving patients completed the follow-up questionnaire. There were no statistically significant differences in preoperative characteristics between the patients who completed and who didn't complete the 12 year follow-up surveys. The enrolment of the patients is summarized in Fig. 1.

The main focus of the study was to evaluate the effect of postoperative complications occurring after CABG operation during primary and secondary hospital stay on patients' QoL and survival. The complications were predefined and included: 1) Resternotomy (due to bleeding or low-out put syndrome), 2) mediastinitis (deep sternal wound infection requiring debridement), 3) sternal or graft harvest site wound infection (symptomatic collection of pus or dehiscence of the wound requiring debridement), 4) gastrointestinal complication (radiologically and clinically verified cholecystitis, pancreatitis, ileus or acute mesentery ischemia), 5) stroke (clinically and radiologically verified by experienced neurologist), 6) acute kidney failure (in need of dialysis or increase of serum creatinine level more than 2-fold from baseline value), 7) pneumonia (causing clinical symptoms and radiologically verified), 8) pulmonary embolism (radiologically verified) 9) prolonged ventilatory support (> $36 \mathrm{~h}$ ), 10) pleural effusion (radiologically verified and requiring treatment), 11) respiratory failure (in need of intubation or mechanical ventilation support), 12) atrial fibrillation (newly diagnosed by ECG requiring cardioversion or permanent anticoagulation), 13) ventricular tachycardia or bradyarrhythmia (requiring 
Table 1 Demographic data and clinical characteristics of the 1128 patients operated during the study period

\begin{tabular}{|c|c|c|c|c|}
\hline & \multicolumn{2}{|c|}{ Total number of included patients $=508$} & & \multirow{3}{*}{$\begin{array}{l}\text { Total number of excluded patients } \\
=620\end{array}$} \\
\hline & No complications & Any complications & & \\
\hline & \multicolumn{3}{|l|}{ MACCE } & \\
\hline & $\begin{array}{l}\text { Number of } \\
\text { patients(\%) }\end{array}$ & $\begin{array}{l}\text { Number of patients } \\
(\%)\end{array}$ & $\begin{array}{l}\text { Number of patients } \\
(\%)\end{array}$ & Number of patients \\
\hline Total number & $303(60)$ & $205(40)$ & $73(14)$ & 620 \\
\hline Mean age, years [SD] & $60.5[9.1]$ & $65.0[9.0]$ & $67.2[8.7]$ & $66.5[9.5]$ \\
\hline Male & $255(84)$ & $165(80)$ & $57(78)$ & 204 \\
\hline \multicolumn{5}{|l|}{ Operative priority } \\
\hline Elective & $248(82)$ & $151(74)$ & $55(75)$ & 288 \\
\hline Urgent or emergency & $55(18)$ & $54(26)$ & $18(25)$ & 293 \\
\hline Euroscore 1 mean [SD] & $2.1[2.0]$ & $3.5[2.7]$ & $4.1[2.5]$ & $4.65[3.0]$ \\
\hline Ejection fraction $<50 \%$ & $51(17)$ & $41(20)$ & $19(27)$ & 166 \\
\hline Left main stem $>50 \%$ & $55(18)$ & $52(25)$ & $15(21)$ & 140 \\
\hline Redo surgery & $8(3)$ & $18(9)$ & $8(11)$ & 27 \\
\hline History of stroke & $5(2)$ & $15(7)$ & $5(7)$ & 43 \\
\hline History of TIA & $8(3)$ & $8(4)$ & $1(1)$ & 35 \\
\hline $\begin{array}{l}\text { History of acute myocardial } \\
\text { infarction }\end{array}$ & $130(43)$ & $84(41)$ & $30(41)$ & 178 \\
\hline $\begin{array}{l}\text { impaired kidney function krea > } \\
141 \mathrm{mmol}\end{array}$ & $2(1)$ & $5(2.5)$ & $2(3)$ & 18 \\
\hline Off-pump surgery & $45(15)$ & $11(5)$ & $4(6)$ & 58 \\
\hline Diabetes & $36(12)$ & $38(19)$ & $8(11)$ & 119 \\
\hline Obesity & $55(18)$ & $45(22)$ & $13(20)$ & 143 \\
\hline History of general ASO & $18(6)$ & $19(9)$ & $9(12)$ & 52 \\
\hline COPD & $15(5)$ & $18(9)$ & $3(4)$ & 49 \\
\hline Persistent AF & $6(2)$ & $11(5)$ & $1(1)$ & 20 \\
\hline Hyperlipidemia & $223(74)$ & $149(73)$ & $50(69)$ & 443 \\
\hline Hypertension & $147(49)$ & $121(59)$ & $45(62)$ & 346 \\
\hline
\end{tabular}

MACCE Major adverse cardiac and cerebrovascular event, TIA Transcient ischemic attack, ASO Arteriosclerosis obliterans, COPD Chronic obstructive pulmonary disease, AF Atrial fibrillation

intensive care unit (ICU) or cardiac care unit (CCU) stay), 14) low out put syndrome (requiring the use of intra aortic balloon or prolonged need for inotropic medication), 15) Perioperative myocardial infarction (including new $\mathrm{Q}$ wave in electrocardiogram and a peak CK-MB level of more than $150 \mu \mathrm{mol} / \mathrm{l})$, 15) postpericardiotomy syndrome (including fever, new or worsening pericardial and pleural effusion) and 16) delirium (deterioration of neuropsychological status requiring medication). Each patient within complication group could have had one or more postoperative complication. Major adverse cardiac and cerebrovascular events (MACCE), including re-sternotomy, mediastinitis, stroke, acute kidney failure and perioperative myocardial infarction, were also analyzed as an independent group. QoL and survival of patients with MACCE were compared with patients without
MACCE, which included patients with other complications than MACCE or no complications.

The primary outcome of the study was health-related QoL which was assessed with Finnish adaption of RAND 36 generic health - related QoL scale. RAND-36 is a validated and widely used scale for which there are reference values available for Finnish population [6]. It comprises scores for eight different dimensions of health-related QoL: 1) general health, 2) physical functioning, 3) role functioning/physical 4) bodily pain, 5) emotional well-being, 6) role functioning/emotional 7) social functioning and 8) energy [7, 8]. The scores for each domain range from 0 to 100,0 being the poorest and 100 the best possible health status. In addition, two summary scores can also be used: the physical component summary (PCS) including the mean value of physical sub-scales, whilst mental component summary 


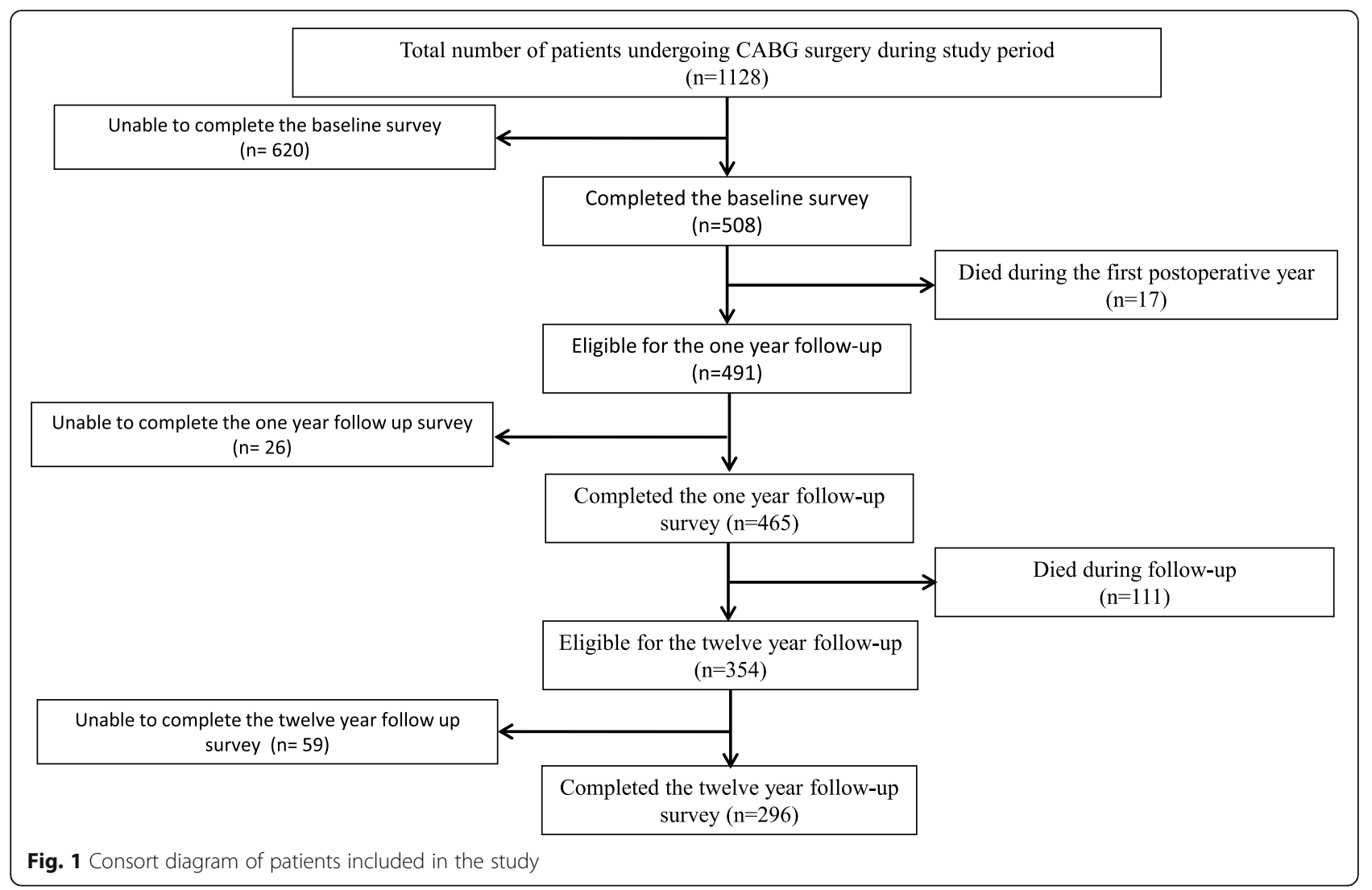

(MCS) equals subscales (5-8) reflecting psychosocial health status [9-11].

Patients and outcome variables are mostly expressed as proportions of the total (in percentage), and continuous variables as means with standard deviation (SD). Categorical variables between the groups were compared by using chi-square test. Continuous variables were analysed with Mann-Whitney test. Baseline, 1 year and 12year follow-up scores for QoL were compared using paired-samples t-test. PCS and MCS scores were compared in three time points with variance analysis for repeated measures. The Kaplan-Meier survival curves of assessed patient groups were compared using log-rank test. Statistical analyses were performed with SPSS 20.0 for Windows (IBM).

\section{Results}

Three hundred and ninety operations out of the 508 included in the analysis were performed electively and 110 (22\%) urgently. Eighty-two percent of all patients were male and patients age varied between 34 to 92 years (median 63). Preoperative characteristics of all patients are shown in Table 1. In this study cohort, patients with complications were older (median age 66 vs. 60 years $p<0.001$ ), had higher Euroscore 1 risk sum (median 3 vs. $2 p<0.001)$, had more often history of stroke $(7.3 \%$ vs. $1.7 \% p=0.002)$, hypertension $(59.0 \%$ vs $49.0 \% p=$ $0.02)$, persistent atrial fibrillation $(5.0 \%$ vs. $2.0 \% p=$ $0.037)$, diabetes ( 19 vs. $12 \% p=0.04$ ) and were more often operated as a redo surgery $(9.0 \%$ vs $3.0 \% p=$ 0.002 ). Otherwise both groups were closely similar in terms of preoperative characteristics. Patients with MACCE were older (median 69 vs. 62 years $p<0.001$ ), had higher Euroscore 1 risk sum (median 4 vs $2 p<$ 0.001 ) and were more often operated as a redo surgery ( $11 \%$ vs. $4.0 \% p=0.002)$ in comparison to patients without MACCE.

The types and frequencies of complications within the patient cohort are described in Table 2. In the total cohort of 508 patients, 205 patients (40\%) experienced at least one of the complications included in our analysis. Seventy-three patients (14\%) had MACCE during postoperative period.

Thirty-day, 1-year and 10-year survival rates were 97\% (7 deaths), 95\% (11 deaths), 72\% (58 deaths) in patients with complication and 99\% (2 deaths), 98\% (5 deaths), $84 \%$ (49 deaths) in patients without complications, respectively. Patients with complications had lower survival rates than patients without complication (log rank $p<0.001)$. Moreover, thirty-day, 1 -year and 10-year survival rates were $90 \%$ (7 deaths), 89\% (8 deaths) and 64\% (26 deaths) in patients with MACCE. Hospital- 
Table 2 Number of patients with intra- and postoperative complication following CABG surgery in 508 patients included in the study $^{\mathrm{a}}$

\begin{tabular}{|c|c|c|c|}
\hline & Total cohort $N=508$ & 1 year $n=465$ & Responders at 12 years $n=296$ \\
\hline \multicolumn{4}{|l|}{ Complication } \\
\hline No & 303 & 276 & 193 \\
\hline Yes & 205 & 189 & 103 \\
\hline MACCE & 73 & 62 & 33 \\
\hline Re-sternotomy & 15 & 11 & 6 \\
\hline Bleeding & 13 & 10 & 5 \\
\hline Low out put syndrome & 2 & 1 & 1 \\
\hline Mediastinitis & 9 & 8 & 2 \\
\hline Stroke & 15 & 13 & 6 \\
\hline Renal failure or dialysis & 19 & 14 & 6 \\
\hline Perioperative myocardial infarction & 22 & 20 & 14 \\
\hline Wound infection & 69 & 66 & 32 \\
\hline Superficial sternal wound infection & 12 & 12 & 6 \\
\hline Graft harvest site & 57 & 54 & 26 \\
\hline Gastrointestinal complication & 4 & 4 & 2 \\
\hline Pneumonia & 9 & 9 & 4 \\
\hline Atrial fibrillation & 19 & 19 & 12 \\
\hline Respiratory failure & 12 & 10 & 7 \\
\hline Tachycardia or bradyarrhythmia & 47 & 42 & 24 \\
\hline Pleural effusion & 24 & 22 & 13 \\
\hline Delirium & 20 & 19 & 9 \\
\hline Low output syndrome & 12 & 7 & 4 \\
\hline Prolonged postoperative ventilatory support & 12 & 11 & 5 \\
\hline Postpericardiotomy syndrome & 10 & 10 & 4 \\
\hline Pulmonary embolism & 7 & 7 & 3 \\
\hline
\end{tabular}

${ }^{a}$ Number of complications may exceed the number of patients when patients had more than one complication

catchment-area matched controls had a 10-year survival rate of $77 \%$. In comparison with age-, sex- and hospitalcatchment-area matched controls, only patients without complications had higher ten-year survival. Figs. 2 and 3 show Kaplan-Meier survival curves for all patient groups.

The RAND- 36 QoL mean scores in patients with and without complications and MACCE are shown in Table 3. The studied patient groups had inferior preoperative baseline QoL values when compared to Finnish general population. One year after surgery, all groups showed higher health scores in all eight QoL dimensions, but in the later follow-up period their scores deteriorated. Twelve years after bypass grafting, patients without complications maintained significant improvements in all but one RAND-36 dimensions (in general health), whereas patients with complications showed statistically significant long-term improvements in all but three different dimensions (in general health, emotional role functioning and energy). Furthermore, patients with
MACCE maintained higher QoL score only in four RAND- 36 dimensions (in physical functioning, physical role functioning, emotional role functioning and pain). Patients with no complications showed higher QoL scores in all RAND-36 dimensions in comparison with age- and sex-matched reference values. The patients with complications and MACCE had elevated health status only in few QoL dimensions, when compared with reference population scores. Above all, changes in physical role functioning and pain were most notable in all patient groups.

Both patients with and without complications showed statistically significant improvements in RAND-36 PCS $(p<0.001)$ and MCS $(p<0.001)$ summary scores 1 and 12 years after CABG surgery compared with their preoperative scores (Table 4). Both groups had high physical and mental summary scores 1 year after surgery. In the late follow-up both PCS and MCS scores were lower. Patients with complications showed deeper decline in their MCS scores $(p=0.004)$ and PCS scores $(p=0.052)$ 


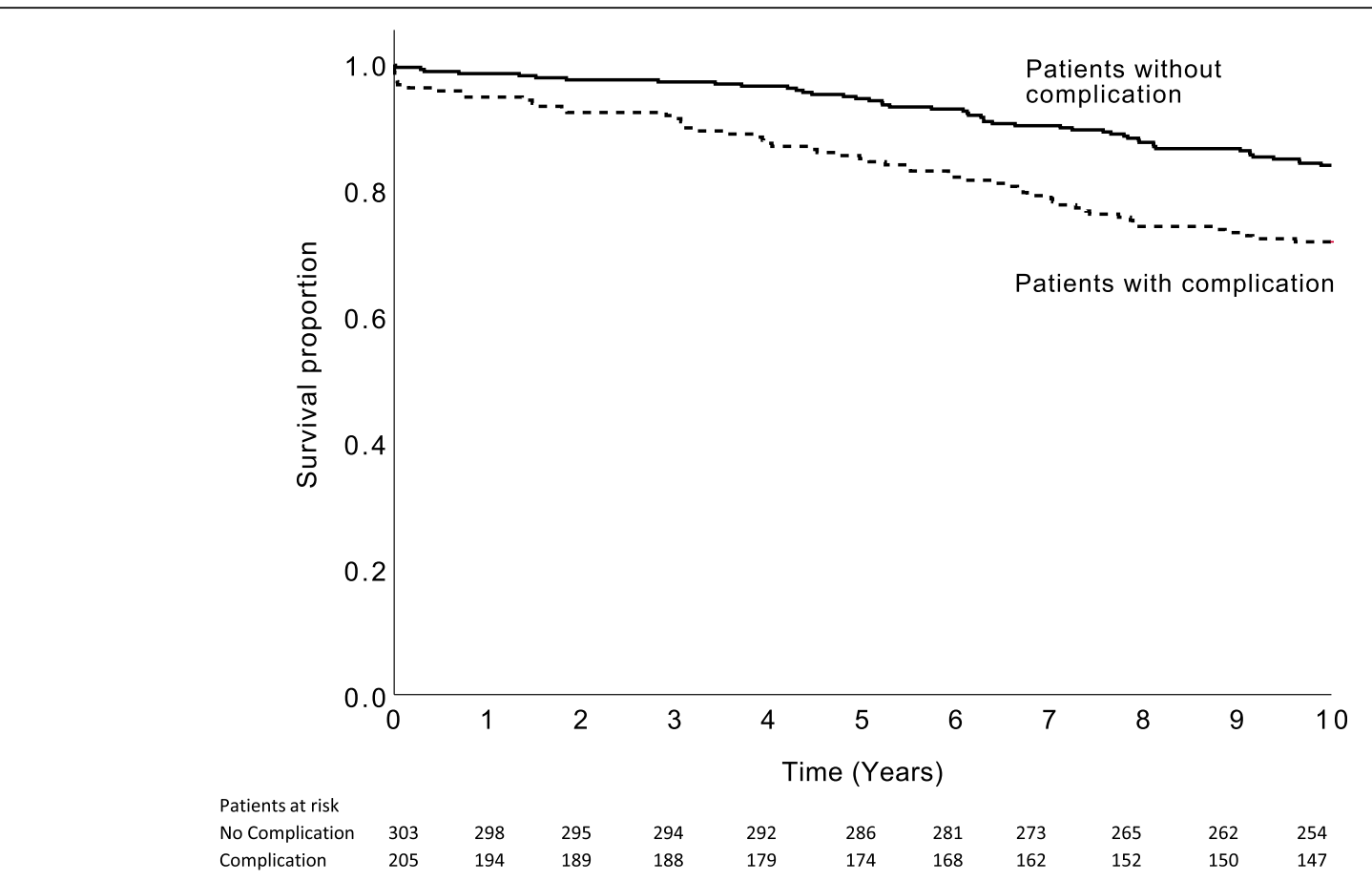

Fig. 2 Kaplan-Meier survival curves for patients with and without complications (Log rank <0.001)

whilst patients without complications maintained their perceived QoL score status better. However, these groups showed elevated QoL score status even 12 years after the surgery when compared with their preoperative values. Patients with MACCE improved their PCS $(p<0.001)$ and $\operatorname{MCS}(p=0.004)$ scores 1 and 12 years after surgery. However, patients with MACCE had lower PCS $(p=0.02)$ and $\operatorname{MCS}(p=0.069)$ scores compared with patients with no MACCE 1 and 12 years after the CABG surgery.

\section{Discussion}

Under the past few decades, the risk profile of patients undergoing isolated CABG has significantly evolved towards higher age with more preoperative comorbidities [4]. Furthermore, CABG has remained the most commonly used treatment for high risk patients with complex CAD $[12,13]$. Despite the steady improvements in survival and operative safety, postoperative complications still cause significant morbidity and suffer among

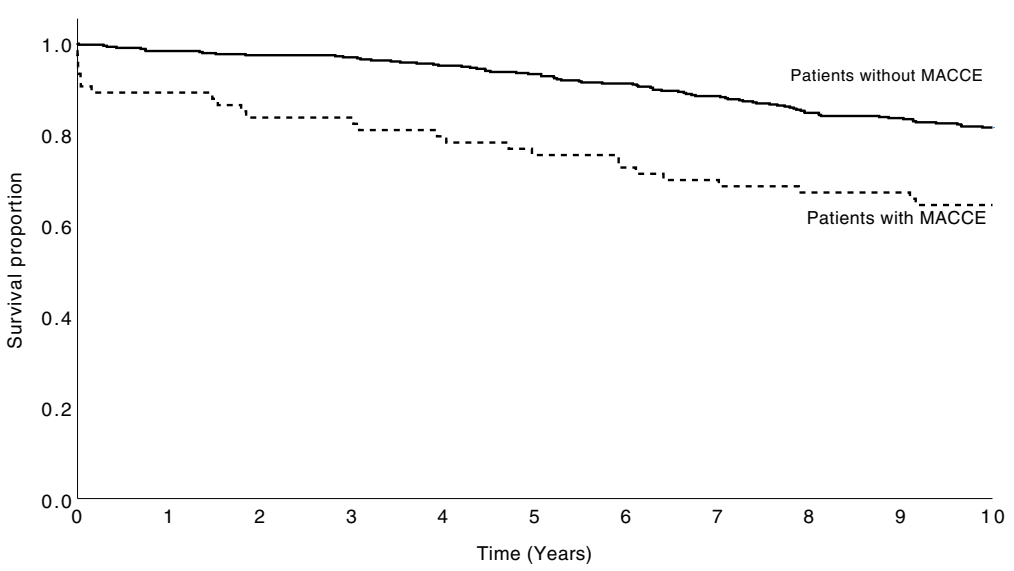

Patients at risk

$\begin{array}{lccccccccccc}\text { No MACCE } & 435 & 427 & 423 & 421 & 413 & 405 & 396 & 384 & 368 & 363 & 354 \\ \text { MACCE } & 73 & 65 & 61 & 61 & 58 & 55 & 53 & 51 & 49 & 49 & 47\end{array}$

Fig. 3 Kaplan-Meier survival curves for patients with and without major cardiac and cerebrovascular events (MACCE) (Log rank < 0.001) 
Table 3 Quality of life scores (RAND 36) for survivors and general population

\begin{tabular}{|c|c|c|c|c|c|c|c|}
\hline QOL category & Group & $\begin{array}{l}\text { Baseline } \\
n=508\end{array}$ & $\begin{array}{l}\text { 1-year follow-up } \\
n=465\end{array}$ & $\begin{array}{l}\text { 12-year follow-up } \\
n=296\end{array}$ & $\begin{array}{l}\text { General } \\
\text { population }^{a}\end{array}$ & Change $^{b}$ & $\begin{array}{l}p \text { - } \\
\text { values }\end{array}$ \\
\hline \multirow[t]{3}{*}{ General health } & No complication & 53.3 & 58.3 & 56.8 & 46.7 & 3.5 & 0.22 \\
\hline & Complication & 48.8 & 52.1 & 48.8 & & 0 & 0.20 \\
\hline & MACCE & 48.9 & 54.3 & 52.6 & & 3.7 & 0.70 \\
\hline \multirow[t]{3}{*}{ Physical functioning } & No complication & 50.4 & 77.4 & 68.9 & 58.7 & 18.5 & $<0.001$ \\
\hline & Complication & 43.8 & 68.1 & 57.6 & & 13.8 & $<0.001$ \\
\hline & MACCE & 42.7 & 68.9 & 54.0 & & 11.3 & 0.011 \\
\hline \multirow[t]{3}{*}{ Social functioning } & No complication & 67.7 & 83.5 & 81.5 & 75.7 & 13.8 & $<0.001$ \\
\hline & Complication & 64.7 & 77.5 & 68.9 & & 4.2 & $<0.001$ \\
\hline & MACCE & 62.3 & 77.9 & 64.6 & & 2.3 & 0.44 \\
\hline \multirow[t]{3}{*}{ Role functioning/physical } & No complication & 22.9 & 60.2 & 56.8 & 39.1 & 33.9 & 0.04 \\
\hline & Complication & 18.2 & 45.5 & 40.2 & & 22 & $<0.001$ \\
\hline & MACCE & 15.8 & 44.8 & 34.9 & & 19.1 & 0.002 \\
\hline \multirow[t]{3}{*}{ Role functioning/emotional } & No complication & 43.5 & 66.0 & 66.9 & 51.3 & 23.4 & $<0.001$ \\
\hline & Complication & 37.7 & 62.0 & 47.4 & & 9.7 & $<0.001$ \\
\hline & MACCE & 35.8 & 65.5 & 42.8 & & 7 & $<0.001$ \\
\hline \multirow[t]{3}{*}{ Emotional well-being } & No complication & 73.3 & 77.5 & 78.9 & 71.8 & 5.6 & 0.001 \\
\hline & Complication & 72.2 & 74.9 & 70.4 & & -1.8 & 0.246 \\
\hline & MACCE & 72.0 & 74.7 & 69.2 & & -2.8 & 0.366 \\
\hline \multirow[t]{3}{*}{ Energy } & No complication & 58.3 & 67.9 & 66.8 & 59.4 & 8.5 & $<0.001$ \\
\hline & Complication & 54.0 & 63.5 & 54.8 & & 0.8 & 0.42 \\
\hline & MACCE & 53.4 & 64.3 & 53.4 & & 0 & 0.83 \\
\hline \multirow[t]{3}{*}{ Pain } & No complication & 50.6 & 76.4 & 74.6 & 63.5 & 24 & $<0.001$ \\
\hline & Complication & 44.7 & 72.5 & 64.9 & & 20.2 & $<0.001$ \\
\hline & MACCE & 44.6 & 73.8 & 64.1 & & 19.5 & $<0.001$ \\
\hline
\end{tabular}

${ }^{\mathrm{a}} \mathrm{Age}$ and sex-adjusted reference values for 12-year follow-up scores. ${ }^{\mathrm{b}}$ Between 12-year and baseline scores. ${ }^{\mathrm{C}}$ Paired-samples $\mathrm{t}$ test between the baseline and 12year follow-up scores

Table 4 Mean change in RAND-36 physical component summary (PCS) and mental component summary (MCS) scores of the study patients in relation to occurrence of postoperative complications

\begin{tabular}{|c|c|c|c|c|c|c|c|}
\hline & \multirow[b]{2}{*}{ Group } & \multirow[b]{2}{*}{ Baseline } & \multirow[b]{2}{*}{1 year } & \multirow[b]{2}{*}{12 years } & \multicolumn{2}{|l|}{$P$-values ${ }^{a}$} & \multirow[b]{2}{*}{ Group } \\
\hline & & & & & Interaction between time*group & Time & \\
\hline \multirow[t]{4}{*}{ PCS scores } & No complication & 47.1 & 70.5 & 64.9 & 0.052 & $<0.001$ & $<0.001$ \\
\hline & Complication & 41.3 & 63.3 & 53.6 & & & \\
\hline & No MACCE & 45.8 & 68.8 & 62.0 & 0.505 & $<0.001$ & 0.02 \\
\hline & MACCE & 39.2 & 61.1 & 52.5 & & & \\
\hline \multirow[t]{4}{*}{ MCS scores } & No complication & 62.7 & 76.0 & 74.2 & 0.004 & $<0.001$ & 0.001 \\
\hline & Complication & 58.0 & 72.2 & 61.6 & & & \\
\hline & No MACCE & 61.5 & 75.1 & 70.8 & 0.301 & 0.004 & 0.069 \\
\hline & MACCE & 57.1 & 70.7 & 61.5 & & & \\
\hline
\end{tabular}

${ }^{a}$ Variance analysis for repeated measures 
operated patients $[5,14]$. The impact of postoperative complications is mainly evaluated in survival [14, 15] and economical [16] perspectives. However, the effect of postoperative complications on patients' quality of life in long term is hitherto unclear. In this prospective cohort study, we evaluated the impact of postoperative complications on long-term Qol and survival. Special interest was focused on the impact of major adverse cardiac and cerebrovascular events on patients' postoperative QoL health-status.

The main finding of our study is that despite the on ongoing deterioration, patients with and without complications and MACCE had higher QoL score status at 1year and even 12-years after CABG surgery. However, patients without complications maintained their perceived QoL best whereas patients with complications had slightly lower QoL scores 1 year and as long as 12 years after the surgery.

The effect of severe postoperative complications on QoL has remained controversial in previous studies. Major complications have shown to cause impaired postoperative QoL after CABG surgery [17-19]. Peric and colleagues found postoperative complications to be an independent predictor of impaired QoL 6 months after CABG surgery [20]. Moreover, Herlizt et al. demonstrated that postoperative complications such as prolonged stay at ICU, prolonged ventilator time and postoperative use of inotropics predict inferior QoL even after 15 years of after CABG operation [21]. On the contrary, Karhunen and colleagues reported that the long-term QoL of the patients, who survived after emergency re-sternotomy and resuscitation, was similar in comparison to patients without major postoperative complications [22]. In addition, Williams and co-authors found that $83 \%$ of patients, who had survived after CABG and related prolonged ICU stay had normal QoL 2 years after surgery [23]. We found that patients with major complications had lower PCS and MCS summary scores at 1 year and 12 years' follow-up and these patients had deeper decline in their QoL status in comparison to patients without MACCE. However, encouragingly, patients with MACCE showed elevated QoL summary scores even 12 years after the surgery compared with preoperative values.

The incidence of postoperative complications after CABG surgery ranges between 30 and $40 \%$ depending on the number of different complication included in the studies $[14,15,20]$. These findings are in line with the incidence of postoperative complication, $40 \%$, represented in our study cohort. The mechanisms behind complications causing impaired QoL can only be speculated upon. Firstly, postoperative complications often prolong primary hospital stay [14], and can cause recurrent hospital readmissions $[14,24]$ which may delay and interfere with the patients' rehabilitation progress. Additionally, major complications and prolonged ICU stay can exposure patients to excessive stress reactions which may cause impaired mental and physical QoL [25]. Moreover, postoperative complications may deteriorate patients' QoL status by causing long lasting local symptoms and physical deficit, such as chronic sternal pain after mediastinitis [26] or physical disability after stroke [27].

A wide range of health measurement tools have been developed to assess health related quality of life, of which Nottingham Health profile (NPH) [28], RAND-36 item health survey [7], the Medical Outcomes study short form (SF36) [8] and EuroQoL (EQ-5D) [29] are most commonly used. We selected the Finnish version of RAND-36 health surveys since it has been carefully validated and contains age and sex-adjusted reference values for the Finnish general population. These reference values originate from the studies of randomly selected population samples from The Finnish Population Register [6].

There are several limitations in our present study. Firstly, all emergently operated patients and those who were unable to complete the baseline survey were excluded from the study. This selection bias may limit the interpretation of the result mainly to electively and urgently treated patients. Yet, the study design was prospective and the follow-up of the study cohort was complete in 95 and $84 \%$ of patients at 1 year and 12 years, respectively, which partly reduces the impact of selection. Secondly, the study is possibly affected by survival bias since patients who survived over 12 years after CABG surgery with or without complications might have had better physical and mental health status than those, who died earlier. This could partly explain why our study population showed higher QoL scores in comparison to age- and sex-adjusted reference population. Thirdly, in addition to postoperative complications, other, non-cardiac medical comorbidities and adverse health events are shown to have a negative impact on patients' health status after CABG surgery, especially in the long term follow-up [30]. Therefore we compared patients' QoL scores with reference values of Finnish general population.

\section{Conclusions}

Despite of ongoing decline 12 years after CABG surgery, both patients with and without complications showed steady improvements in their health-related QoL when compared with the preoperative scores. However, the patients with complications and especially with MACCE had lower postoperative QoL at 1 year and 12 years after the surgery. Due to far-reaching impact of postoperative complications on patients QoL status, a special focus 
should be directed towards complication prevention and intensive rehabilitation of patients with postoperative complications after CABG surgery.

\section{Abbreviations}

AF: Atrial fibrillation; ASO: Arteriosclerosis obliterans; CABG: Coronary artery bypass grafting; CAD: Coronary artery disease; CCU: Cardiac care unit; COPD: Chronic obstructive pulmonary disease; EQ-5D: EuroQoL:

ICU: Intensive care unit; MACCE: Major adverse cardiac and cerebrovascular events; MCS: Mental component summary; NPH: Nottingham health profile; PCS: Physical component summary; RAND-36: The RAND-36 health survey; SF36: The medical outcomes study short form; TIA: Transcient ischemic attack; QOL: Quality of life

\section{Acknowledgements}

None.

\section{Authors' contributions}

MD Dr. Matti Hokkanen: conception/design of the study, acquisition and analysis/ interpretation of data/ have drafted or revised the work/ major contributor in writing the manuscript. MSc Heini Huhtala: statistical analysis and interpretation of the data. Prof. Dr. Jari Laurikka: have drafted or revised the work. Adj.Prof. Dr. Otso Järvinen: Conception/design of the study/ have drafted or revised the work. All authors read and approved the final manuscript.

\section{Funding}

Not applicable.

\section{Availability of data and materials}

The datasets generated and/or analysed during the current study are not publicly available due to hospital data privacy protocol but are available from the corresponding author on reasonable request.

\section{Declarations}

\section{Ethics approval and consent to participate}

The study has been performed in accordance with the Declaration of Helsinki. The study was approved by the institutional review board of Tampere University and all participating patients gave informed consent.

\section{Consent for publication}

Not applicable.

\section{Competing interests}

None declared.

\section{Author details}

'Department of Cardio-Thoracic Surgery, Tays Heart Hospital, Tampere University Hospital, Tampere, Finland. ${ }^{2}$ Faculty of medicine and health technology, Tampere University, Tampere, Finland. ${ }^{3}$ Faculty of Social sciences, Tampere University, Tampere, Finland.

Received: 14 January 2021 Accepted: 7 May 2021

Published online: 14 June 2021

\section{References}

1. D'Agostino RS, Jacobs JP, Badhwar V, Fernandez FG, Paone G, Wormuth DW, et al. The Society of Thoracic Surgeons adult cardiac surgery database: 2019 update on outcomes and quality. Ann Thorac Surg. 2019;107(1):24-32. https://doi.org/10.1016/j.athoracsur.2018.10.004.

2. Neumann FJ, Sousa-Uva M, Ahlsson A, Alfonso F, Banning AP, Benedetto U, et al. 2018 ESC/EACTS guidelines on myocardial revascularization. Eur Heart J. 2019;40(2):87-165. https://doi.org/10.1093/eurheartj/ehy394.

3. Ferguson TB Jr, Hammill BG, Peterson ED, DeLong ER, Grover FL. STS National Database Committee. A decade of change--risk profiles and outcomes for isolated coronary artery bypass grafting procedures, 19901999: a report from the STS National Database Committee and the Duke Clinical Research Institute. Society of Thoracic Surgeons. Ann Thorac Surg. 2002; $73: 480-9$
4. Cornwell LD, Omer S, Rosengart T, Holman WL, Bakaeen FG. Changes over time in risk profiles of patients who undergo coronary artery bypass graft surgery: the veterans affairs surgical quality improvement program (VASQIP). JAMA Surg. 2015;150(4):308-15. https://doi.org/10.1001/jamasurg.2014.1700.

5. ElBardissi AW, Aranki SF, Sheng S, O'Brien SM, et al. trends in isolated coronary artery bypass grafting: an analysis of the society of thoracic surgeons adult cardiac surgery database. J Thorac Cardiovasc Surg. 2012; 143(2):273-81. https://doi.org/10.1016/j.jtcvs.2011.10.029.

6. Aalto A-M, Aro AR, Teperi J. RAND-36 as a measure of health-related quality of life. reliability, construct validity and reference values in the finnish general population (in Finnish with English Summary). Helsinki: Stakes, Research Reports; 1999. p. 101.

7. Hays RD, Sherbourne CD, Mazel R. The RAND 36-item health Survey1.0. Health Econ. 1993;2(3):217-77. https://doi.org/10.1002/hec.4730020305.

8. Ware JE, Sherbourne CD. The MOS-36-item short-form health survey (SF-36). Med Care. 1992;30(6):473-81. https://doi.org/10.1097/00005650-1 99206000-00002.

9. Hays RD, Stewart AL. The structure of self-reported health in chronic disease patients. Psychological assessment. J Consult Clin Psychol. 1990;58:22-30.

10. Hays RD, Marshall GN, EYI W, Sherbourne CD. Fouryearscross-lagged associations between physical and mental health in the medical outcome study. J Consult Clin Psychol. 1994;62(3):441-9. https://doi.org/10.1037/0022006X.62.3.441.

11. Rumsfeld JS, Magid DJ, O'Brien M, McCarthy M Jr, MacWhinney S, Shroyer ALW, et al. Changes in health-related quality of life following cor- onary artery bypass graft surgery. Ann Thorac Surg. 2001;72(6):2026-32. https://doi. org/10.1016/50003-4975(01)03213-1.

12. Farkouh ME, Domanski M, Sleeper LA, Siami FS, Dangas G, Mack M, et al. Strategies for multivessel revascularization in patients with diabetes. N Engl J Med. 2012;367(25):2375-84. https://doi.org/10.1056/NEJMoa1211585.

13. Serruvs PW, Morice MC, Kappetein AP, Colombo A, Holmes DR, Mack MJ, et al. Percutaneous coronary intervention versus coronary-artery bypass grafting for severe coronary artery disease. N Engl J Med Medicine. 2009; 360(10):961-72. https://doi.org/10.1056/NEJMoa0804626.

14. Jawitz OK, Gulack BC, Brennan JM, Thibault DP, Wang A, O'Brien SM, et al. Association of postoperative complications and outcomes following coronary artery bypass grafting. Am Heart J. 2020;222:220-8. https://doi. org/10.1016/j.ahj.2020.02.002

15. Freundlich RE, Maile MD, Hajjar MM, Habib JR, Jewell ES, Schwann T, et al. Years of life lost after complications of coronary artery bypass operations. Ann Thorac Surg. 2017;103(6):1893-9. https://doi.org/10.1016/j.athoracsur.2 016.09.048.

16. Brown PP, Kugelmass AD, Cohen DJ, Reynolds MR, Culler SD, Dee AD, et al. The frequency and cost of complications associated with coronary artery bypass grafting surgery: results from the United States Medicare program. Ann Thorac Surg. 2008;85(6):1980-6. https://doi.org/10.1016/j.athoracsur.2 008.01.053.

17. Gaudino M, Girola F, Piscitelli M, Martinelli L, Anselmi A, Della Vella C, et al. Long-term survival and quality of life of patients with prolonged postoperative intensive care unit stay: unmasking an apparent success. J Thorac Cardiovasc Surg. 2007;134(2):465-9. https://doi.org/10.1016/j.jtcvs.2 007.04.028.

18. Lagercrantz E, Lindblom D, Sartipy U. Survival and quality of life in cardiac SurgeryPatients with prolonged intensive care. Ann Thorac Surg. 2010;89(2): 490-5. https://doi.org/10.1016/j.athoracsur.2009.09.073.

19. Diab MS, Bilkhu R, Soppa G, Edsell M, Fletcher N, Heiberg J, et al. The influence of prolonged intensive care stay on quality of life, recovery, and clinical outcomes following cardiac surgery: a prospective cohort study. J Thorac Cardiovasc Surg. 2018;156(5):1906-15. https://doi.org/10.1016/j.jtcvs.2 018.05.076.

20. Peric V, Borzanovic M, Stolic R, Jovanovic A, Sovtic S, Dimkovic S, et al. Predictors of worsening of patients' quality of life six months after coronary artery bypass surgery. J Card Surg. 2008;23(6):648-54. https://doi.org/1 0.1111/j.1540-8191.2008.00667.x.

21. Herlitz J, Brandrup-Wognsen G, Evander MH, Libungan B, Sjöland H, Caidahl K, et al. Quality of life 15 years after coronary artery bypass grafting. Coron Artery Dis. 2009;20(6):363-9. https://doi.org/10.1097/MCA.0b013e32832c8ced.

22. Karhunen JP, Jokinen JJ, Raivio PM, Salminen US. Long-term survival and quality of life after cardiac resuscitation following coronary artery bypass grafting. Eur J Cardio-thoracic Surg. 2011;40(1):249-54. https://doi.org/10.101 6/j.ejcts.2010.10.042. 
23. Williams MR, Wellner RB, Hartnett EA, Thornton B, Kavarana MN, Mahapatra $R$, et al. Long-term survival and quality of life in cardiac surgical patients with prolonged intensive care unit length of stay. Ann Thorac Surg. 2002; 73(5):1472-8. https://doi.org/10.1016/50003-4975(02)03464-1.

24. Fox JP, Suter LG, Wang K, Wang Y, Krumholz HM, Ross JS. Hospital-based, acute care use among patients within 30 days of discharge after coronary artery bypass surgery. Ann Thorac Surg. 2013;96(1):96-104. https://doi.org/1 0.1016/j.athoracsur.2013.03.091.

25. Schelling G, Richter M, Roozendaal B, Rothenhäusler HB, Krauseneck T, Stoll $C$, et al. Exposure to high stress in the intensive care unit may have negative effects on health-related quality-of-life outcomes after cardiac surgery. Crit Care Med. 2003;31(7):1971-80. https://doi.org/10.1097/01.CCM. 0000069512.10544 .40$.

26. Jidéus L, Liss A, Ståhle E. Patients with sternal wound infection after cardiac surgery do not improve their quality of life. Scand Cardiovasc J. 2009;43(3): 194-200. https://doi.org/10.1080/14017430802573098.

27. Salazar JD, Wityk RJ, Grega MA, Borowicz LM, et al. Stroke after cardiac surgery: short-and long-term outcomes. Ann Thorac Surg. 2001;72(4):1195201.

28. Hunt SM, McKenna SP, Mceven J, Williams J, Papp E. The Nottingham health profile: subjective health status and medical consultations. Soc Sci Med. 1981:15A:221-9.

29. The EuroQol Group. EuroQoL - a new facility for the measurement of health-related quality of life. Health Policy. 1990;16:199-208.

30. Gao D, Grunwald GK, Rumsfeld JS, Schooley L, MacKenzie T, Shroyer ALW. Time-varying risk factors for long-term mortality after coronary artery bypass graft surgery. Ann Thorac Surg. 2006;81(3):793-9. https://doi.org/10.1016/j.a thoracsur.2005.08.005.

\section{Publisher's Note}

Springer Nature remains neutral with regard to jurisdictional claims in published maps and institutional affiliations.

Ready to submit your research? Choose BMC and benefit from:

- fast, convenient online submission

- thorough peer review by experienced researchers in your field

- rapid publication on acceptance

- support for research data, including large and complex data types

- gold Open Access which fosters wider collaboration and increased citations

- maximum visibility for your research: over $100 \mathrm{M}$ website views per year

At $\mathrm{BMC}$, research is always in progress.

Learn more biomedcentral.com/submissions 